\title{
Design and Structural Thermal Analysis of Gas Turbine Rotor Blade with Radial Holes using Solidworks
}

\author{
K Vidya Sagar ${ }^{1}$, Dr. N. Mahesh Kumar ${ }^{2}$, P. Siva Ram ${ }^{3}$ \\ ${ }^{1}$ M.Tech Student, ${ }^{2}$ Professor, ${ }^{3}$ Assistant Professor \\ Sri Venkateswara College of Engineering and Technology, Andhra Pradesh, India
}

\section{ABSTRACT}

Cooling of gas turbine blades are major attention to high temperature working conditions. Numerous methods have been recommended for the cooling of blades and a unique technique is to be used to ensure radial holes to pass high velocity cooling air along the blade span. The forced convection heat transfer from the blade to the cooling air, it will reduce the temperature of the blade to permissible limits. Finite element analysis is used in the present work to examine steady state thermal \&amp; structural performance for stainless steel. Four different models comprising of solid blade and blades with varying number of holes $(7,8,9$ \&amp; 10 holes) were evaluated in this project to find out the optimum number of cooling hole. It is observed that as the number of holes increases the temperature distribution will be increased consequently. The structural analysis is carried out after the thermal analysis in SOLID WORKS SIMULATION TOOL. It is observed that blade with 10 holes has showing more stresses than the remaining blades. Finally the blade with 9 holes has giving optimum performance for prescribed loading conditions with average temperature of $513.9 \mathrm{~K}$, heat flux of $3.118 \mathrm{~W} / \mathrm{m} 2$ at the trailing edge and von misses stresses as 17.67 $\mathrm{MPa}$.

KEY WORDS: Gas Turbine, Structural Analysis, Thermal Analysis, Modal, Finite Element Analysis

\section{INTRODUCTION}

A turbine, from the Greek $\tau$ vo $\rho \beta \eta$, tyrbē, ("turbulence"), is a rotary mechanical device that extracts energy from a fluid flow and converts it into useful work. A turbine is a turbomachine with at least one moving part called a rotor assembly, which is a shaft or drum with blades attached. Moving fluid acts on the blades so that they move and impart rotational energy to the rotor. Early turbine examples are windmills and waterwheels.

Gas, steam, and water turbines usually have a casing around the blades that contains and controls the working fluid. Credit for invention of the steam turbine is given both to the British engineer Sir Charles Parsons (1854-1931), for invention of the reaction turbine and to Swedish engineer Gustaf de Laval (1845-1913), for invention of the impulse turbine. Modern steam turbines frequently employ both reaction and impulse in the same unit, typically varying the degree of reaction and impulse from the blade root to its periphery.

The word "turbine" was coined in 1822 by the French mining engineer Claude Burdin from the Latin turbo, or vortex, in a memoir, "Des turbines hydrauliquesou machines rotatoires à grandevitesse", which he submitted to the Académieroyale des sciences in Paris. Benoit Fourneyron, a former student of Claude Burdin, built the first practical water turbine

\section{Operation theory:}

A working fluid contains potential energy (pressure head) and kinetic energy (velocity head). The fluid may be compressible or incompressible. Several physical principles are employed by turbines to collect this energy:

Impulse turbines change the direction of flow of a high velocity fluid or gas jet. The resulting impulse spins the turbine and leaves the fluid flow with diminished kinetic energy. There is no pressure change of the fluid or gas in the turbine blades (the moving blades), as in the case of a steam or gas 
turbine; the entire pressure drop takes place in the stationary blades (the nozzles). Before reaching the turbine, the fluid's pressure head is changed to velocity head by accelerating the fluid with a nozzle. Pelton wheels and de Laval turbines use this process exclusively. Impulse turbines do not require a pressure casement around the rotor since the fluid jet is created by the nozzle prior to reaching the blading on the rotor. Newton's second law describes the transfer of energy for impulse turbines.

Reaction turbines develop torque by reacting to the gas or fluid's pressure or mass. The pressure of the gas or fluid changes as it passes through the turbine rotor blades. A pressure casement is needed to contain the working fluid as it acts on the turbine stage(s) or the turbine must be fully immersed in the fluid flow (such as with wind turbines). The casing contains and directs the working fluid and, for water turbines, maintains the suction imparted by the draft tube. Francis turbines and most steam turbines_use this concept. For compressible working fluids, multiple turbine stages are usually used to harness the expanding gas efficiently. Newton's third law describes the transfer of energy for reaction turbines.

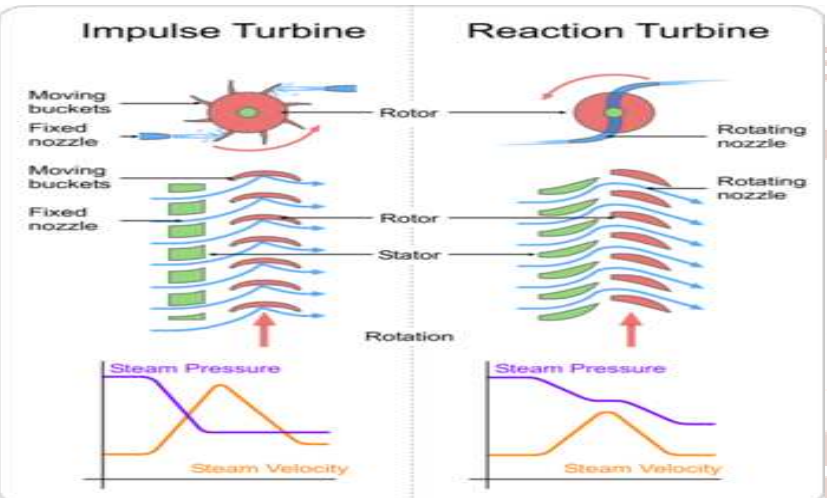

Figure 1: Impulse and reaction turbine

\section{INTRODUCTION TO GAS TURBINE}

The gas turbine is the most versatile item of turbomachinery today. It can be used in several different modes in critical industries such as power generation, oil and gas, process plants, aviation, as well domestic and smaller related industries. A gas turbine essentially brings together air that it compresses in its compressor module, and fuel, that are then ignited. Resulting gases are expanded through a turbine. That turbine's shaft continues to rotate and drive the compressor which is on the same shaft, and operation continues. A separator starter unit is used to provide the first rotor motion, until the turbine's rotation is up to design speed and can keep the entire unit running. The compressor module, combustor module and turbine module connected by one or more shafts are collectively called the gas generator.

\section{LITERATURE REVIEW}

Mohammad H. Albeirutty: in their paper discussed that the heat transfer analysis of gas turbine blades using air or steam as coolants is investigated under various operating conditions. A general model of the combined system is developed and is used to compare the performance of three main schemes of the blade cooling, namely air-cooling, open-circuit steam cooling (OCSC) and closed-loop steam cooling (CLSC). The heat transfer model permitted the calculations of the cooling mass ratio that is required to reach a certain blade temperature. The results showed that steam appears to be a potential cooling medium, when employed in an open-circuit or in a closed-loop scheme. The combined system with CLSC gives better overall performance than does aircooling or the OCSC.

Gowrishankar: in their paper discussed that Withstanding of gas turbine blades for the elongations is a major consideration in their design because they are subjected to high tangential, axial, centrifugal forces during their working conditions. The first stage rotor blade of a two - stage gas turbine has been analyzed for structural, thermal using ANSYS 12 which is powerful Finite Element Software. In the process of getting the thermal stresses, the temperature distribution in the rotor blade has been evaluated using this software. This project specifies how the program makes effective use of the ANSYS pre-processor to analyze the complex turbine blade geometries and apply boundary conditions to examine steady state thermal \& structural performance of the blade for $\mathrm{N} 155$, Hastealloy $\mathrm{x}$ \& Inconel 625 materials.

\section{MODELLING OF GAS TURBINE}

Modeling of Blade in SolidWorks:

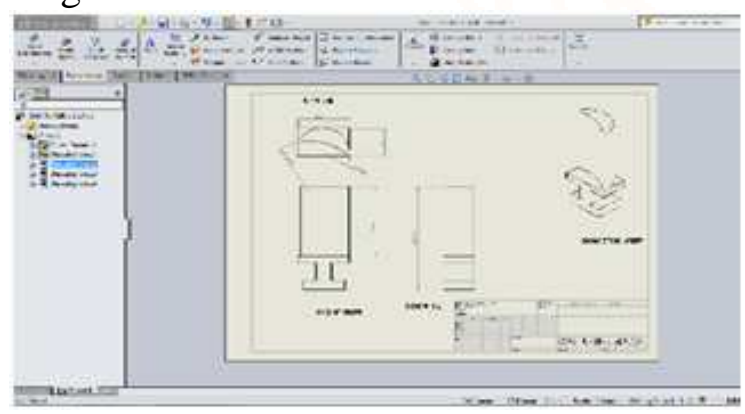

Figure 2: orthographic views of gas turbine blade 
Now the gas turbine blade with holes $7,8,9$ and 10 has been modeled as shown below

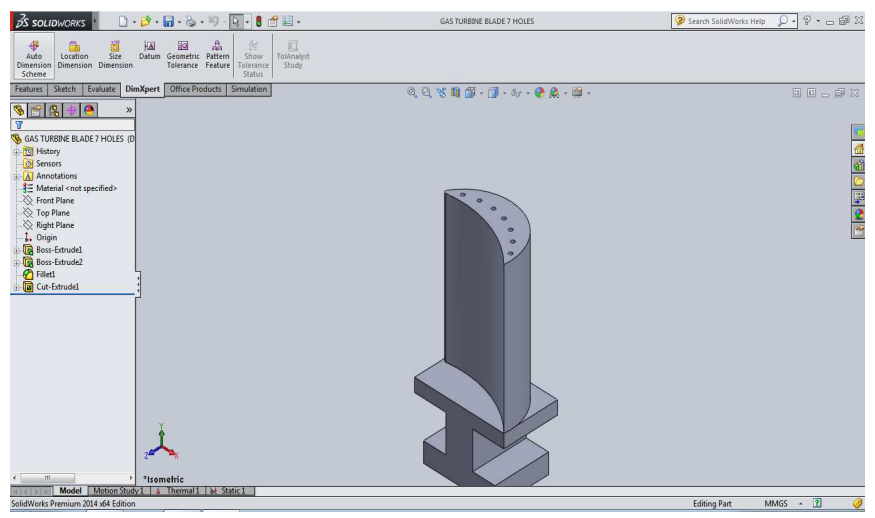

Figure 3: Gas turbine blade of 7 holes

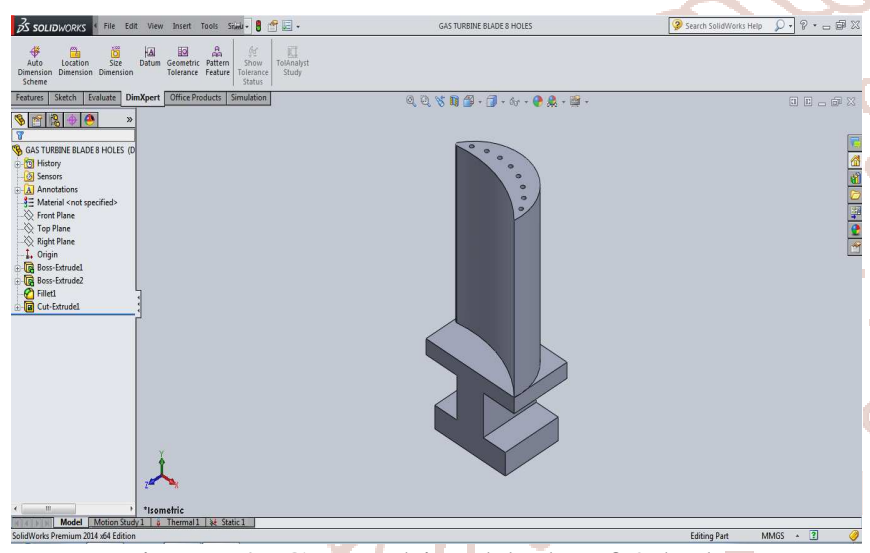

Figure 4: Gas turbine blade of 8 holes

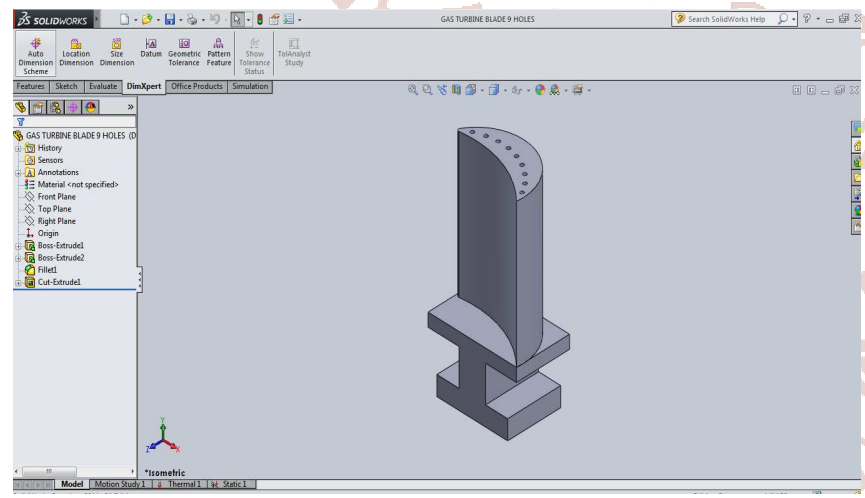

Figure 5: Gas turbine blade of 9 holes

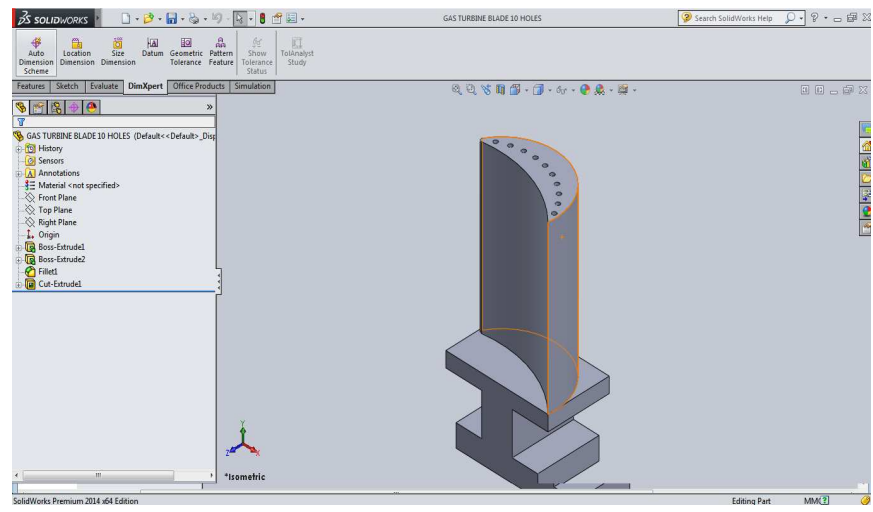

Figure 6: Gas turbine blade of 10 holes
Table1. Types of simulations in SolidWorks

\begin{tabular}{|c|c|c|c|}
\hline $\begin{array}{l}\text { Study } \\
\text { type }\end{array}$ & Study icon & $\begin{array}{l}\text { Study } \\
\text { type }\end{array}$ & $\begin{array}{l}\text { Study } \\
\text { icon }\end{array}$ \\
\hline Static & $\phi^{*}$ & $\begin{array}{l}\text { Modal } \\
\text { Time } \\
\text { History }\end{array}$ & $\omega$ \\
\hline Frequency & $\mathrm{Q}^{\mathrm{H}}$ & Harmonic & $\infty$ \\
\hline Buckling & $q$ & $\begin{array}{c}\text { Random } \\
\text { Vibration }\end{array}$ & 4 \\
\hline Thermal & $q$ & $\begin{array}{l}\text { Response } \\
\text { Spectrum }\end{array}$ & $\Delta$ \\
\hline $\begin{array}{l}\text { Design } \\
\text { Study }\end{array}$ & 9P & $\begin{array}{c}\text { Drop } \\
\text { Test }\end{array}$ & d. \\
\hline $\begin{array}{c}\text { Nonlinear } \\
\text { Static }\end{array}$ & $k_{\bar{z}}$ & Fatigue & 中 \\
\hline $\begin{array}{l}\text { Nonlinear } \\
\text { Dynamic }\end{array}$ & & $\begin{array}{l}\text { Pressure } \\
\text { Vessel } \\
\text { Design } \\
\end{array}$ & बा \\
\hline
\end{tabular}

\section{Static Analysis:}

When loads are applied to a body, the body deforms and the effect of loads is transmitted throughout the body. The external loads induce internal forces and reactions to render the body into a state of equilibrium. Linear Static analysis calculates displacements, strains, stresses, and reaction forces under the effect of applied loads.

\section{Thermal Stress Analysis:}

Changes in temperature can induce substantial deformations, strains, and stresses. Thermal stress analysis refers to static analysis that includes the effect of temperature.

Perform thermal stress analysis using one of the following options:

> Using a uniform rise or drop in temperature for the whole model.

Using a temperature profile resulting from a steady state or transient thermal analysis.

- Using a temperature profile from Flow Simulation

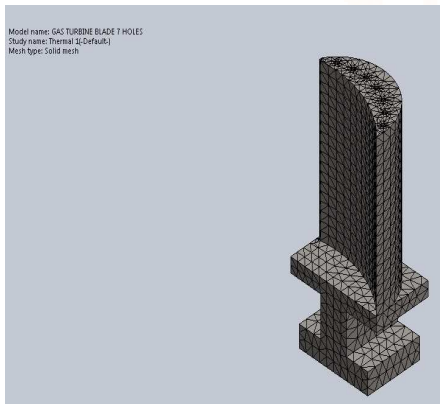

Figure 7: Meshed model of gas turbine blade with 7 holes 
International Journal of Trend in Scientific Research and Development (IJTSRD) ISSN: 2456-6470 Table2. Mesh Information

\begin{tabular}{|l|l|}
\hline Mesh type & Solid Mesh \\
\hline Mesh Used: & Standard mesh \\
\hline Automatic Transition: & Off \\
\hline Include Mesh Auto Loops: & Off \\
\hline Jacobian points & 4 Points \\
\hline Element Size & $6 \mathrm{~mm}$ \\
\hline Tolerance & $0.42672 \mathrm{~mm}$ \\
\hline Mesh Quadity & High \\
\hline
\end{tabular}

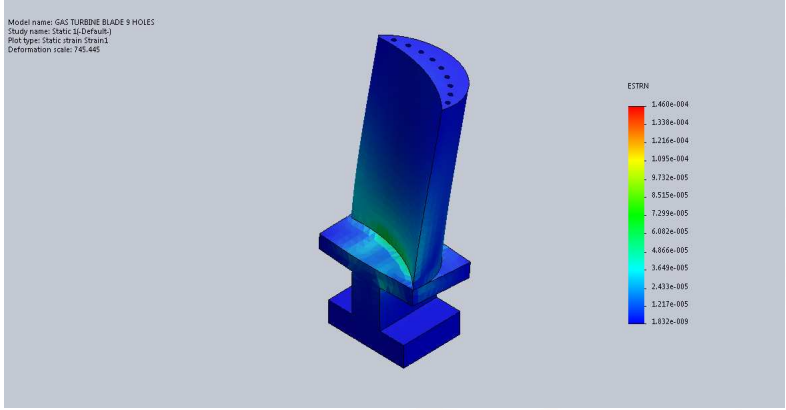

Figure 11: Strain

VI. THERMAL ANALYSIS OF GAS TURBINE BLADE

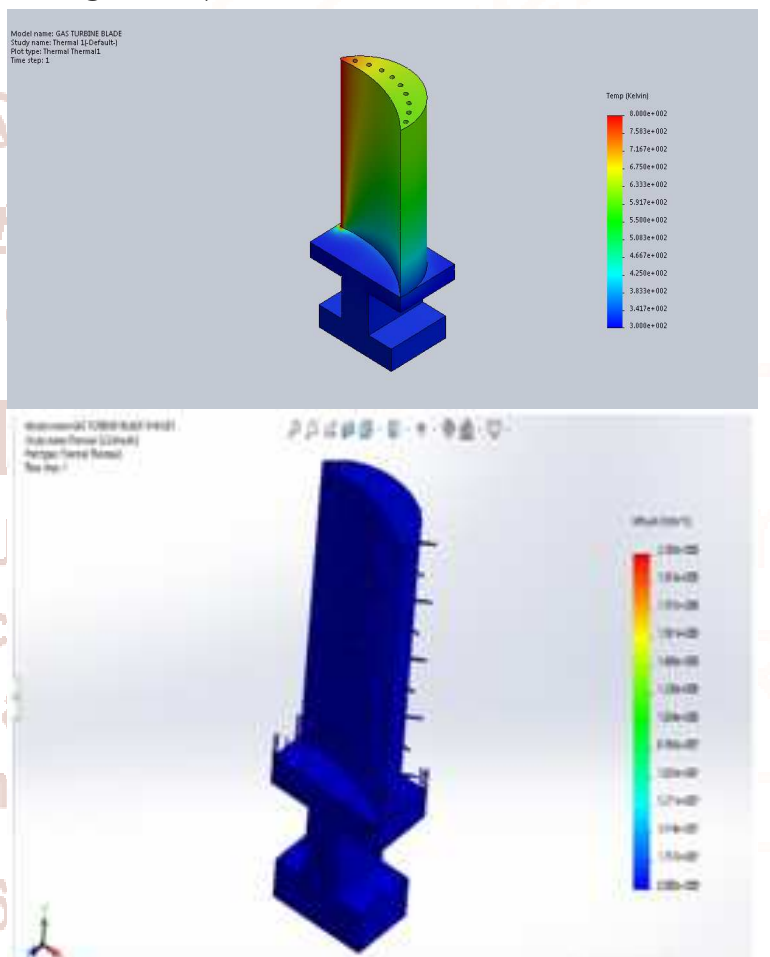

Figure 12: Heat Flux of Gas Turbine

\section{RESULTS}

Table 3: comparison of average temperatures at the trailing edge of blades with different holes

\begin{tabular}{|c|c|}
\hline Blade with holes & $\begin{array}{c}\text { Average temperature } \\
\text { at the trailing edge }\end{array}$ \\
\hline 7 holes blade & $516.1 \mathrm{k}$ \\
\hline 8 holes blade & $515.12 \mathrm{k}$ \\
\hline 9 holes blade & $513.9 \mathrm{k}$ \\
\hline 10 holes blade & $513.2 \mathrm{k}$ \\
\hline
\end{tabular}

Table 4: comparison of Heat flux developed in blades

\begin{tabular}{|c|c|}
\hline Blade with holes & A verage Heat-Flux \\
\hline 7 holes blade & $2.999 \mathrm{w} / \mathrm{m}^{2}$ \\
\hline 8 holes blade & $3.447 \mathrm{w} / \mathrm{m}^{2}$ \\
\hline 9 holes blade & $3.118 \mathrm{w} / \mathrm{m}^{2}$ \\
\hline 10 holes blade & $4.263 \mathrm{w} / \mathrm{m}^{2}$ \\
\hline
\end{tabular}

Figure10: Displacement 
International Journal of Trend in Scientific Research and Development (IJTSRD) ISSN: 2456-6470

Table 5: comparison of von misses stresses developed in blades Blade with holes $\quad$ Von misses stresses [Mpa]

\begin{tabular}{|c|c|}
\hline 7 holes & 15.6 \\
\hline 8 holes & 19.6 \\
\hline 9 holes & 17.67 \\
\hline 10 holes & 28.6 \\
\hline
\end{tabular}

\section{CONCLUSION}

In this project using finite element analysis as a tool, the thermal and structural analysis is carried out sequentially. The blade with different no. of holes 7 , 8, 9and 10 were used for analysis.

$>$ The gas turbine blade is modeled in a 3D cad tool called Solidworks 2014by using extrude feature.

$>$ Then gas turbine blade with different holes such as 7, 8, 9 and 10 has been modeled on the blade span.

$>$ The blade with different no. of holes 7, 8, 9and 10 were used for thermal analysis in SolidWorks simulation tool. It is observed that as the no. of holes increases the temperature distribution increase.

$>$ The structural analysis is carried out after the thermal analysis in SOLID WORKS SIMULATION TOOL. It is observed that blade with 10 holes has showing more stresses than the remaining blades.

\section{REFERENCES}

1. Gowreesh, S., Sreenivasalu Reddy, N. and Yogananda Murthy, NV. 2009. Convective Heat Transfer Analysis of a Aero Gas Turbine Blade Using Ansys, International Journal of Mechanic and Solids. 4: 39-46.

2. Facchini, B. and Stecco. S.S. 1999.Cooled expansion in gas turbines: a comparison of analysis methods, Energy Conversion and Management. 40: 1207-1224.

3. Mohammad, H., Albeirutty. Abdullah, S., Alghamdi., Youssef, S. Najjar. 2004. Heat transfer analysis for a multistage gas turbine using different blade-cooling scheme, Applied Thermal Engineering. 24: 563-577.

4. Mahfoud, K. and George, B. 1997. Computational study of turbine blade cooling by slot-injection of a gas, Applied Thermal Engineering. 17: 1141-1149.

5. Moyroud, F., Fransson, T. and Jacquet-Richardet, G. 2002. A comparison of two finite element reduction techniques for mistuned bladed-disks, Journal of Engineering for Gas Turbines and Power. 124: 942-953.

6. Giovanni, C., Ambra, G., Lorenzo, B. and Roberto, F. 2007Advances in effusive cooling techniques of gas turbines, Applied Thermal Engineering. 27: 692-698.

7. Cun-liang, L., Hui-ren, Z., Jiang-tao, B. and Duchun, X. 2010.Film cooling performance of converging slot-hole rows on a gas turbine blade, International Journal of Heat and Mass Transfer.53: 5232-5241.

8. Zhang, JJ., Esat, II. And Shi, YH. 1999. Load Analysis with VaryingMesh Stiffness, Computers and Structures. 70: 273-280.

9. Hildebrabd, FB. 1997. Introduction to Numerical Analysis, McGraw-Hill, New York.

10. MoussaviTorshizi, SE., YadavarNikravesh, SM. and Jahangiri,A. 2009. Failure analysis of gas turbine generator cooling fan blades, Engineering Failure Analysis. 16: 1686-1695.

11. Cleeton, JPE., Kavanagh, RM. and Parks, GT. 2009. Blade cooling optimization in humid-air and steam-injected gas turbines, Applied Thermal Engineering. 29: 3274-3283.

12. Krishnamoorthy, C. 1994. Finite Element Analysis Theory and Programming, Tata McGraw-Hill, New Delhi.

13. Martin, HC. and Carey, GF. 2006. Introduction to the Finite Element Analysis, McGraw Hill Publishing Co Ltd, New Delhi. 